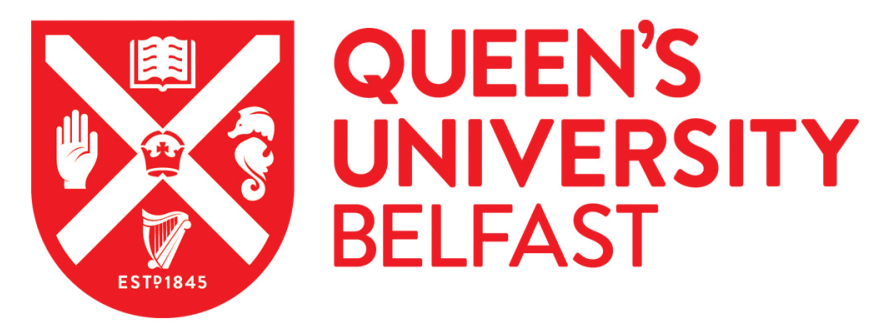

\title{
Using Participant-Produced Drawings as an Alternative to Photographs in Ethnographic Research
}

Mazzetti, A. (2020). Using Participant-Produced Drawings as an Alternative to Photographs in Ethnographic Research. In S. Dodd (Ed.), Ethics and Integrity in Visual Research Methods (Vol. 5). (Advances in research ethics and integrity). Emerald Group Publishing Ltd..

Published in:

Ethics and Integrity in Visual Research Methods

Document Version:

Peer reviewed version

Queen's University Belfast - Research Portal:

Link to publication record in Queen's University Belfast Research Portal

Publisher rights

Copyright 20xEmerald Publishing Limited.

This work is made available online in accordance with the publisher's policies. Please refer to any applicable terms of use of the publisher.

\section{General rights}

Copyright for the publications made accessible via the Queen's University Belfast Research Portal is retained by the author(s) and / or other copyright owners and it is a condition of accessing these publications that users recognise and abide by the legal requirements associated with these rights.

Take down policy

The Research Portal is Queen's institutional repository that provides access to Queen's research output. Every effort has been made to ensure that content in the Research Portal does not infringe any person's rights, or applicable UK laws. If you discover content in the Research Portal that you believe breaches copyright or violates any law, please contact openaccess@qub.ac.uk. 
Using Participant-Produced Drawings as an Alternative to Photographs in Ethnographic Research

\section{Angela Stephanie Mazzetti}

\section{INTRODUCTION}

\section{INSERT FIGURE 1 HERE}

The image above is the result of my lack of technical knowhow as my flash reflects off the glass picture frame I am attempting to photograph. Although my face is obscured by the camera, my identity is unwittingly revealed as my very distinctive coat and hair colour may potentially reveal my identity to those who know me, have met me, or who have seen other published images of me. And yet, preserving anonymity is a key principle underpinning ethical research in the social sciences (Wiles, Crow, Heath \& Charles 2007). Addressing this issue requires that researchers do not disclose participants' identities and also that researchers fully brief their research participants as to the extent to which anonymity can or cannot be assured in the dissemination and publication of research outputs (Wiles, Prosser, Bagnoli, Clark, Davies, Holland \& Renold, 2008).

The use of photographs, specifically those produced by research participants, presents researchers with a number of ethical challenges regarding both participant anonymity and data integrity (see Wiles et al. 2008 for a more comprehensive review of the issues). First, photographs taken by participants may present researchers with images that capture people in public spaces who have not given their consent for their image to be used (Wiles et al., 2008) or participants may capture images of people engaged in unlawful or immoral activities (Clark, Prosser \& Wiles, 2010). Furthermore, although participants may take photographs for the specific purposes of the research study to which they have been recruited, they may personally use the images for their own purposes which may involve the unrestricted sharing of images on social media platforms without peoples' identities being concealed (Wiles et al., 2008).

Second, photographs taken by research participants may present researchers with issues of internal confidentiality (Pink, 2007; Wiles et al., 2008). In the context of ethnographic research, researchers are working within defined, often small communities. As such, photographs taken within these communities (whether taken by the researcher or the participants), may render members of those communities easily recognisable to one another (Banks, 2007; Rose, 2007; Surmiak, 2018). Even when photographs have been manipulated to disguise the faces of individuals (for 
example through blurring or pixilation), participants may still be recognisable to others through their clothes, distinctive jewellery or physical features such as tattoos (Wiles at al., 2008). Furthermore, contextual background information (such as a street name or a building) may also unwittingly reveal identities (Prosser \& Loxley, 2008). As such, using photographs as a method of data capture, may render the process of anonymity (of people and places) more challenging as there is a greater likelihood of identification (Clark et al., 2010; Wiles at al., 2008).

In this chapter, I discuss these ethical challenges by reflecting on my own research experiences of using visual methods. In particular, I refer to my recent ethnographic study of stress appraisal and coping in post-conflict Northern Ireland, a study in which I decided to use participant-produced drawings as an alternative to participant-produced photographs. This decision was strongly influenced by the social, cultural and political context of my research; a context in which I considered that the taking of photographs had the potential to inflict harm (in both the short-term and the long-term) on my research participants. This chapter is structured in four parts. First, I present an overview of the general ethical challenges of using visual methods in ethnographic research. Second, I provide an overview of my research context and how this context accentuated my desire to protect my research participants' identities. Third, I put forward the rationale for using participantproduced drawings as an alternative to photographs. Finally, based on my own research experiences, I put forward some suggestions that other researchers engaged in similar research may find useful.

\section{THE ETHICAL CHALLENGES OF USING PARTICIPANT PRODUCED- PHOTOGRAPHS IN ETHNOGRAPHIC RESEARCH}

Ethnography is the study of people in their normal social and cultural settings with the objective of establishing the meanings that people assign to their everyday activities (Hammersley \& Atkinson, 2007). The role of the ethnographer is to bring their participants' worlds 'to life' for those unfamiliar with the research setting (Madden, 2017); a process that relies on a communicative trust and dialogue between ethnographer and participants (O'Reilly, 2009). Visual methods are a longestablished method of data collection in ethnographic research (Emmisson \& Smith, 2000; Pink, 2007) complementing other ethnographic research methods such as 
observations and interviews (Prosser \& Loxley, 2008). Visual methods encompass the use of photographs, video, internet pages, drawings, and visual representations (Prosser \& Loxley, 2008). Photographs as a data collection method, have been widely used in ethnographic research as visual imagery is seen as being central to our perceptions and interpretations of our everyday social lives (Pauwels, 2008). As such, photographs are a powerful means of capturing meaning and sense-making as they often reveal more about our participants' worlds than simply textual data alone (Collier \& Collier, 1986; Pink, 2007). Photographs comprise 'found data' (for example, archival photographs or family albums), researcher-produced data (photographs taken by the researcher), and participant-produced data (photographs taken by research participants for the specific purposes of the research project) (Prosser \& Loxley, 2008, p. 5).

Contemporary approaches to ethnography advocate collaborative research between ethnographer and participants in the co-production of data, a move away from traditional, colonial, and paternalistic approaches to ethnography which placed the researcher as the independent and objective observer of the life of others (Pink, 2007). From this traditional perspective, the visual was used as a means of supporting ethnographers' claims and interpretations of the lives of others (Collier \& Collier, 1986). A contemporary and collaborative approach to ethnography encourages a mutually trusting relationship between participants and researcher (Banks, 2001; Pink, 2007), which facilitates participant agency and voice, empowering participants to present their world as they see it and experience it (Allen, 2015; Banks, 2001; Pink, 2007). As such, participant-produced photographs have become widely used in ethnographic research as a means for participants to share their perspectives of their worlds (Allen, 2015). However, this paradigm shift in the use of photography raises a number of ethical challenges for ethnographic researchers specifically related to participant anonymity and data integrity.

Obscuring photographs through digital manipulation (such as pixilating, cropping or applying black-out bars to faces), before dissemination and publication, is a common way that researchers anonymise photographs to protect the identity of research participants (Allen, 2015; Wiles, Coffey, Robinson \& Heath, 2012). However, altering images is problematic. First, tampering with an image may compromise the integrity of the data (Allen, 2015; Pauwels, 2008; Wiles at al., 2012). Afterall, ethnographers adopt visual methods because images have the potential to 
portray richer contextual information than textual data alone (Banks, 2001; Pink, 2007; Rose, 2007). As such, tampering with an image may erase this essential contextual information that it set out to capture in the first place (Prosser \& Loxley, 2008; Wiles at al., 2012). For example, obscuring a person's face also obscures the meaning behind the image, resulting in the loss of an essential facet of the image (Allen, 2015). Afterall, what value does a blurred face add to an interpretation of meaning? (Clark et al.. 2010). As such, obscuring an image results in important nonverbal information such as facial expressions (Pauwels, 2008) or emotion and feeling (Wiles et al., 2008) being lost.

Second, contextual or background information may render obscuring the face pointless (Clark et al., 2010; Pauwels, 2008). For example, reflecting on his 'connected lives' project, Andrew Clark (cited in Wiles et al., 2008) highlights that even though he had anonymised both his participants and the name of the field site, those who were familiar with the research setting were able to recognise themselves and others in the photographs. Third, obscuring facial features is a contentious issue in the social sciences, (Sweetman, 2008) juxtaposing on the one hand, participant empowerment and voice, and on the other, researcher paternalism (Allen, 2015). Individuals and communities may want to be identified and therefore obscuring their faces is disconcerting, disrespectful, and objectifying (Allen, 2015; Wiles et al., 2008). Furthermore, the masking of the face may have negative social connotations associated with crime or victimhood (Wiles et al., 2008).

However, Pink (2007) argues that there is a tension between participants' rights to decide how their images will be used and the ethnographer's responsibility to inform participants of the implications of their decisions. She highlights that participants may not be cognisant of the norms and conventions of the research world and therefore they need to be informed of the potential outlets (such as conference papers, books, and visual displays) where their images might be shared. In an era of open access, there is an additional risk that photographs will be further distributed, distorted and misrepresented outside of their original research setting (Mannay, 2014) as they are shared and re-used through cyberspace (Prosser \& Loxley, 2008). Once an image enters the public domain, it is difficult to remove it (Banks, 2001). As such, Pink (2007) stresses that researchers need to take responsibility for the outcomes of their research and in certain contexts, this may involve anonymising images to protect themselves and their participants. 
Finally, ethnographers need to be aware of the social, cultural and political contexts in which their photographs may be viewed and interpreted (Pink, 2007;

Prosser \& Loxley, 2008). Such contexts will inform research ethical decision making about how, when and if photographs should be taken and published (Pink, 2007; Langmann \& Pick, 2014; Wiles, Coffey, Robinson, \& Prosser, 2012). As such, researchers need to be sensitive to the situational demands of the research setting and be responsive and adaptable in addressing ongoing ethical challenges (Browne \& Moffett, 2014). Guillemin \& Gillam (2004) make the distinction between procedural ethics (the practices mandated by ethical review panels) and ethics in practice (the ongoing ethical concerns that researchers face when in the field). Lester \& Anders (2018) suggest that procedural ethics may fail to anticipate the ethical dilemmas encountered in visual research and as such, researchers need to make ongoing decisions about what is ethically correct in a given context. This has specific significance in the context of sensitive research ${ }^{1}$ (Lee, 1993), research involving vulnerable groups (Surmiak 2018), or research in conflict and post-conflict societies (Browne \& Moffett, 2014; Dawson, 2007; Ganiel, 2013).

\section{THE IMPORTANCE OF MAINTAINING PARTICIPANT ANONYMITY IN ETHNOGRAPHIC RESEARCH}

Between July 2016 and December 2018, I conducted an ethnographic study with a group of participants who had grown up in what can be categorised as the Belfast Metropolitan Area. ${ }^{2}$ The purpose of the study was to explore the long-term emotional impact of coping with the Troubles. Many lives in Northern Ireland were affected by the Troubles, the term euphemistically given to a 30-year period of intrastate conflict which lasted from the civil unrest and mobilisation of British troops in 1969 until the signing of the Good Friday / Belfast Agreement in 1998 (Dixon \& O'Kane, 2011; Dunn, 1995). During the Troubles, over 3,700 people were killed and over 40,000 were injured (Smyth \& Hamilton, 2003). In a small geographical area

\footnotetext{
${ }^{1}$ Lee (1993, p. 3) defines sensitive research as research that has the potential to be intrusive (for example the study of emotion-laden topics); incriminating (such as the study of deviant behaviours); or political (for example studies of coercion or power struggles). Lee further highlights that "sensitivity" is situationally and culturally defined and as such, "normal" research may trespass into sensitive territory as the situational context of the research evolves.

${ }^{2}$ An area that extends from Belfast city centre southwards to Lisburn and northwards to Carrickfergus on the Antrim coast, and Bangor on the Down coast.
} 
with a relatively small population, it is estimated that one in two people lost a friend or acquaintance to the violence and one in ten, a family member (Gallagher, 2014). The protracted and vicious nature of the conflict has left deep emotional scars (Bolton, 2017; Dawson, 2007; McKay, 2008) and even after twenty years since the signing of the Good Friday / Belfast Agreement, the emotional legacy of the Troubles continues to impact the region as Northern Ireland attempts to come to terms with its past and build a peaceful future (Dawson, 2007).

Although I considered that my research was not political with a capital $P$ (Ganiel, 2013), the situational and temporal context of my research cast a political shadow over my research. My fieldwork took place during a volatile political period in Northern Ireland which saw the marginalisation of the middle of the road political parties, the collapse of the Northern Ireland Assembly, Brexit and with it, the threat of the reintroduction of a "hard border" between Northern Ireland and the Republic of Ireland. In addition, my fieldwork coincided with commemorative events of significance to the political landscape of Northern Ireland, such as the fiftieth anniversary of the civil rights marches, the twentieth anniversary of the signing of the Belfast / Good Friday Agreement, and the centenary anniversaries of both the Battle of the Somme and the Easter Risings.

Dixon \& O'Kane (2011) highlight that, although there is consensus that the region is now more peaceful, what remains contested is how secure that peace is. As one of my research participants noted, "old wounds never really heal in Northern Ireland, they just fester under the surface, and each time they break open, they are harder to repair." In this temporal and situational context, talking about the Troubles continues to be a controversial and contentious issue. There are different narratives as to the cause of the conflict, different narratives as to who should be considered the victims of the conflict, and different narratives as to how to maintain peace in a society with a perceived hardening of sectarian attitudes, ongoing challenges of curbing dissident paramilitary activity, and dealing with the sectarian sticking points (such as flags and parades) (Dawson, 2007; Dixon \& O'Kane, 2011). As such, my study was sensitive both in terms of the intrusive nature of the research topic (emotion, stress and coping) but also in terms of the political sensitivities of conducting research in a post-conflict society.

\section{INSERT FIGURE 2 HERE}


A photograph captures someone's identity in a way that other data collection methods cannot access (Langmann \& Pick 2014) and throughout my research in Northern Ireland, I was frequently reminded of the culture of fear, mistrust, secrecy, and surveillance that still permeates much of Northern Irish society. As an illustration, on my first fieldwork visit to Northern Ireland, I met with an organisation that had used participant-produced photographs to complement participant interviews in their book collection of Troubles-related narratives. However, the original edition of the book had to be destroyed as one of the families had retrospectively decided not to have their story or image made public. This resulted in a revised edition not being available for the book launch and therefore pages had to be physically ripped from the original edition so as to omit the family's story. Later in my fieldwork. I encountered a similar situation with another organisation who had likewise used participant-produced photographs to complement participant interviews. On this occasion, two participants asked for their narratives and pictures to be removed in the final stages of getting the collection ready for publication. One participant was so concerned about the repercussions that the participant asked that all emails, communications, drafts of the story, and photographs be permanently deleted from the organisation's communications systems. Furthermore, at the end of my fieldwork, I encountered a social media news alert relating to an incident in Belfast in which a man had been attacked. The article explicitly referenced the fact that the victim of the attack wanted his identity preserved. The original article included a picture of the victim to illustrate the extent of his injuries, but to protect his identity, the face of the victim was pixelated. However, on subsequent shares of the article on social media, the original pixilation had been removed and the man's face was revealed ${ }^{3}$.

The examples above highlight how the situational context may influence ongoing willingness of research participants to engage with a study. Ethnographic research is a long-term and unpredictable process (Pauwels, 2008). In the context of my research, the changing political climate in the region evoked participants' fears about being identified. Wiles at al. (2008) note that although individuals may be happy for their images to be taken at one point in their lives, they may be less happy if their situational circumstances change. The safety and dignity of research

\footnotetext{
${ }^{3}$ I have decided not to include a picture from the news article as to do so, would perpetuate the matter.
} 
participants is paramount and as such, researchers must be attuned to circumstances under which real harm may be inflicted to participants through the use of visual data (Langmann \& Pick, 2014; Pauwels, 2008). Clark et al. (2010) therefore suggest that researchers need to be aware of their situational contexts and apply this awareness to decide when and when not to use photographs.

This contextual decision-making needs to be embedded throughout the research process, from design through to dissemination and publication (Pauwels, 2008). With regards to my own study, this situational awareness was embedded throughout. For example, even before I commenced the fieldwork phase of my research, I attended an advanced training programme on the ethics of conflict and peace research. This course offered me the opportunity to engage in meaningful debate and discussion on issues related to ethical research in transitional contexts, including the use of photographs. Additionally, I also engaged in pre-fieldwork exposure visits to familiarise myself with the research context. Browne \& Moffett (2014) suggest that pre-fieldwork exposure helps to develop researcher experience, situational awareness and confidence. As part of this pre-fieldwork exposure, as well as visiting Northern Ireland on a regular basis, I also kept up to date with the day-today climate in the region by subscribing to regional news alerts. This situational exposure was instrumental in my decision not to use participant-produced photographs or researcher-produced photographs of my participants or their immediate environments from the start of my fieldwork. I considered that revealing my participants' identities in this manner had the potential to inflict harm both in the short-term and in the longer-term. Finally, my decision not to use photographs was subsequently reinforced through my fieldwork encounters, as outlined above.

Pauwels (2008) warns against a hit and run mentality to the use of visual methods, stressing that if researchers are aware of potential harm to their participants, then regardless of how valuable the method may be, it should not be used.

\section{ADVOCATING THE USE OF PARTICIPANT-PRODUCED DRAWING IN POST- CONFLICT ETHNOGRAPHIC RESEARCH}

Drawing is an ideal visual method for producing data on complex, emotive and multifacets issues that are difficult to articulate verbally (Bagnoli, 2009; Prosser \& Loxley, 2008) such as the topic of stress and coping (Mazzetti \& Blenkinsopp, 2012). This is because drawing provides an outlet for deeply embedded memories and thoughts 
which may not be surfaced through other data collection methods such as interviews (Vince, 1995; Vince \& Brousinne, 1996). Drawing, as a technique, may also liberate participants from cultural taboos about what can be said (Vince, 1995) and as such, drawing may elicit more honest expressions of emotions, feelings, assumptions, beliefs, and biases (Nossiter \& Biberman, 1990). Drawing can facilitates the sensemaking of complex transitions (such as post-conflict transitions) as it enables participants to synthesise events (Barner, 2008) and bring together interrelated memories and experiences (Mazzetti \& Blenkinsopp, 2012). Furthermore, engaging participants in drawing fulfils the ethnographic principles of collaborative research (Pink, 2007) and empowers participants to both determine the content and the voice of the image they produce independent of the researcher (Banks, 2001). As such, participant-produced drawing as a data collection method, elicits similar benefits to participant-produced photographs. However, drawings (as opposed to a photographs) ameliorate the ethical challenge of exposing participants' identities. To illustrate this point, I refer to a participant-produced drawing from my own research. The drawing was produced by the participant after a conversation we had on childhood memories and how these memories inform present-day perceptions of stress.

\section{INSERT FIGURE 3 HERE}

The drawing of the 'Skylight' presented above (along with the participant's interpretation of its meaning and significance) enabled my participant to present a difficult memory from his/her childhood; that of feeling marginalised and under threat of attack, but without revealing his/her identity. For example, biographical data about the participant (in terms of gender, age, or religious affiliation) is not explicit in either the drawing or the participant's explanation of the drawing's meaning. Additionally, although the drawing is of a 'place' and the explanation refers to 'place', there are no location identifiers obvious in either the drawing or the explanation. This is particularly important in ethnographic research within small communities as a photograph of 'place' can easily identify the community to which the participant belongs (Wiles et al., 2008). Finally, the drawing makes no reference to insignia, emblems or colours (such as flags or murals), which are of particular significance in 
Northern Ireland (Jarman, 1999). As such, the drawing is not used to perpetuate a particular stereotype or narrative image regarding the place (Wiles et al., 2008).

However, drawings are not without their own specific practical and ethical challenges. For example, some participants may feel uncomfortable or selfconscious about drawing (Mazzetti and Blenkinsopp, 2012). It is important therefore that the researcher makes it clear that the use of drawing is not a test of participants' artistic skills, but rather a way of empowering participants to visualise rather than verbalise sense-making and meaning (Bagnoli, 2009). The drawing presented above is rather sophisticated in technique and was produced outside of the research interview. As such, the participant was able to take his/her time in putting together the image without any interference from me as the researcher. However, other participants produced less sophisticated but no less meaningful and powerful drawings.

In this study, the participants were able to draw their own images in their own space and own time using whatever artistic medium they preferred. Drawings can also be used within the context of a research interview, however, this approach may put time pressures on the creative process and also restrict the medium to those made available by the researcher. This was an issue I encountered in an earlier research study in which I used visual timelines to explore career transitions. Many of the participants expressed reservations regarding their artistic prowess. I dealt with this issue by encouraging those less confident in drawing, to use emoticons to express their feelings. These emoticons were often embellished to emphasise emotions. For example, adding tears to a sad emoticon or adding a sunshine halo to a happy emoticon. Hybrid emoticons were used by some to express conflicting or mixed emotions, and varying sizes of emoticons were used to illustrate different levels of emotional responses or to symbolise growing or diminishing emotions over time (see Mazzetti \& Blenkinsopp [2012] for a detailed discussion). As such, even those who were unsure about their ability to be artistic were still able to draw insightful images.

Furthermore, ethical issues may arise from drawings if participants choose to include personal or place identifiers within the images (Wiles et al., 2008). It is therefore advisable that researchers encourage participants not to include such identifiers (for example, peoples' names or place names, initials, dates) that may later need to be obscured when the drawings are shared or published. Referring to 
her Reflection on Young Lives project (cited in Wiles et al., 2008), Bagnoli discusses how she needed to alter the participant-produced images (self-portraits, collages, timelines, relational maps) prior to dissemination of the images to remove any identifiers. She also reflects on the aesthetic challenges this presented in terms of giving voice to the young people involved in her study and their artistic efforts whilst at the same time tampering with and changing their artworks to preserve their anonymity. This was also a challenge I encountered in my timelines study. Many of the participants of that study included identifiers in their drawings, presenting me with ethical, technical and financial challenges when disseminating and publishing the drawings. For example, the image used in Mazzetti and Blenkinsopp (2012) required the input of a digital technician with specialist software to remove identifiers (such as names and dates) from the timeline so that the image could be published without revealing the participant's identity. Furthermore, the size of the drawings in the timelines study (A1 sheets of paper) created difficulties with the storage and subsequently, the disposal of the images which required the use of a large format shredder, adding additional costs to the project (see Mazzetti [2014] for a detailed discussion of the issues).

\section{Conclusions}

In this chapter I provide an insight into my decision not to use photographs of my participants or participant-produced photographs. These decisions were driven by the social, political, and cultural context of my research. I considered that using photographs in a post-conflict society had too much potential to harm my participants through the disclosure of their identity. However, I also explore the value of visual methods as they have the capacity to bring rich and multi-faceted insights that cannot be achieved through textual data alone. I, therefore, explore my rationale for the use of participant-produced drawings as an alternative to photographs. I consider that participant-produced drawings elicit many of the benefits of photographs but ameliorate many of the ethical challenges. I also consider that these insights may be transferable to other research contexts. Prosser and Loxley (2008) note that there is a paucity of case study examples of how researchers adopting visual methods make ethically informed decisions. As such, I conclude with a set of ethical considerations 
that researchers in similar contexts may wish to consider as part of their ethical decision making both in context and in practice.

Gaining ethical clearance: At the research design phase it is important that researchers consider the rationale for adopting visual methods. It is worth contemplating at this stage the value that visual data will bring to the research project and how visual data will be captured (for example through photo-elicitation, researcher-produced, or participant-produced images). If the decision is taken to adopt researcher or participant-produced photographs, then consideration must be given to issues of informed consent and anonymity. This decision will require an understanding of the social, cultural and political contexts in which the images will be created, interpreted and disseminated (Pink, 2007). Pre-exposure to the research setting or prior knowledge and understanding of the research setting will support a more informed decision-making process on these issues.

In addition, ethics review panels will need to be presented with a sound rationale for the approach taken along with information on how issues of informed consent and anonymity will be dealt with. This will generally require that all stages of the research process have been considered including data capture, data storage, data sharing, and data dissemination and publication. Even after ethical clearance has been approved, researchers need to be attuned to the tensions between procedural ethics and ethics in practice (Guillemin \& Gillam, 2004), and, as such, researchers will have to make ongoing ethical decisions in the field. The support of a research buddy, supervisor, or director with whom these challenges can be discussed, can facilitate this process. Issues of consent and anonymity are not just appropriate to photographs but also drawings. Additionally, researchers will need to have considered how they will manage the ongoing issues of participant anonymity throughout all stages of the research process.

Informed participants: It is important that researchers reflect on how they will inform research participants as to how their photographs or drawings will be used. This should include information on how these artefacts will be disseminated and published. It is useful to demonstrate this in practice, for example, by showing participants some examples of how their images will be used. This can involve sharing with them a poster, presentation, or publication that has used visuals. This 
process facilitates a better understanding of the journey that their images will take. It is also worthwhile discussing the timeframes associated with this. For example, it may take a few years for their images to be published and participants need to be informed that they are consenting to a long-term process and, at times, quite a dynamic process. Additionally, participants need to be informed that, even after the original artefact has been destroyed, digital images will remain in the public domain infinitum (Banks, 2001). In an age of open access, their images may also be used for further research purposes (Mannay, 2014).

Informed method: The process of data capture must be fully explained to participants. For studies that involve participant-produced photographs, this explanation needs to make reference to what is permissible to photograph and what is off limits. Furthermore, consideration needs to be given to the social, cultural and political context in which the research is situated as different contexts may inform the evaluation of what is acceptable and what is not acceptable to photograph (Pink, 2007). For studies that involve participant-produced drawings, researchers should consider how they will deal with participants' anxieties regarding their ability to draw. This may involve researchers providing different approaches to drawing such as collages, interpretive art, use of colour, self-portraits, timelines, or emoticons (Bagnoli, 2009; Mazzetti \& Blenkinsopp, 2012; Wiles et al., 2008). Researchers may also wish to consider the group production of art that enables participants to work together in teams to co-produce drawings (Barner, 2008).

Anonymising images: Researchers need to reflect on how images will be anonymised. If identifiers are included (regardless of whether photographs or drawings are used) then retrospectively removing identifiers can require technical knowledge and specialist software and may also add additional costs to the research. Thought also needs to be given to how permanent any image manipulation technique may be. For example, the ease with which methods of digital anonymisation (such as blurring or pixilation) can be removed and then re-shared without anonymisation by those with the requisite technical knowledge. Thought also needs to be given to how the images will be used in the future and this may involve a decision not to include some aspects of visual data (Allen, 2015). Furthermore, in research studies that involve defined groups, internal confidentiality 
needs to be considered as individuals and groups may be easily recognisable to one another in such contexts (Prosser and Loxley, 2008).

Participant-informed analysis: Data integrity is an important principle underpinning social sciences research (Clark et al., 2010). The value of using participantproduced visual images is based on the premise that the method empowers participants to present their world as they see it and experience it (Pink, 2007). In deciding to adopt participant-produced images, it is therefore important that researchers consider how they will capture their participants' interpretation of these images. This can be achieved in a number of ways. First, the image may be produced as part of a research interview as in the timelines example discussed above. As part of this process, annotations (made by both the researcher and the participant) were added to the timelines to capture participant meaning throughout the process and also at the end of the interview (see Mazzetti [2014, pp. 9] for a detailed discussion of the process). Second, the participant-produced images may be discussed as part of a research interview, which is recorded and transcribed, to elicit participant meaning (Allen, 2015). Or, participants can add a textual explanation (outside of a research interview setting) to accompany their image. This method was adopted in this study and both the participant-produced drawing and the participantproduced interpretation of its meaning are presented above. 


\section{REFERENCES}

Allen, L. (2015). Losing face? Photo-anonymisation and visual research integrity. Visual Studies, 30 (3), 295-308. doi: 10.1080/1472586X.2015.1016741.

Atkinson, P., Coffey, A., Delamont, S., Lofland, J., \& Lofland, L. (2001). Handbook of Ethnography. London: SAGE Publications Ltd.

Bagnoli, A. (2009). Beyond the standard interview: The use of graphic elicitation and arts-based methods. Qualitative Research, 9, 547-570. doi:10.1177/1468794109343625

Banks, M. (2001). Visual methods in social research. London: Sage.

Banks, M. (2007). Using visual data in qualitative research. London: Sage.

Barner, R. (2008). The dark tower: Using visual metaphors to facilitate emotional expression during organizational change. Journal of Organizational Change Management, 21, 120-137. doi:10.1108/09534810810847075.

Bolton, D. (2017). Conflict, Peace and Mental Health: Addressing the consequences of conflict and trauma in Northern Ireland. Manchester: Manchester University Press.

Brewer, J. D. (2000). Ethnography. Maidenhead, UK: Open University Press.

Browne, B. \& Moffett, L. (2014). Finding Your Feet in the Field: Critical Reflections on Early Career Researchers on Field research in Transitional Societies. Journal of Human Rights Practice, 6 (2), 223-237. doi: 10.1093/jhuman/huu010.

Clark, A, Prosser, J. \& Wiles, R. (2010). Ethical issues in image-based research. Arts and Health, 2 (1), 81-93. doi: 10.1080/17533010903495298.

Collier, J., \& Collier, M. (1986). Visual anthropology: Photography as a research method. Albuquerque, NM: University of New Mexico.

Dawson, G. (2007). Making peace with the past? Memory, trauma and the Irish Troubles. Manchester: Manchester University Press.

Dixon, P. \& O'Kane, E. (2011). Northern Ireland Since 1969. Harlow: Pearson Education Limited

Dunn, S. (1995). Facets of the Conflict in Northern Ireland. Hampshire: McMillan Press Ltd.

Emmison, M. \& Smith, P. (2000). Researching the visual. London: Sage.

Gallagher, A. M. (2014). Psychological Approaches to the Northern Ireland Conflict. Canadian Journal of Irish Studies, 13 (2), 21-32. doi: 10.2307/25512706

Ganiel, G. (2013). Research Ehics in Divided and Violent Societies: Seizing the Ethical Opportunity. Ethics for Graduate Researchers, 167-181. doi: 10.1016/B9780-12-416049-1.00011-8. 
Guillemin, M., \& Gillam, L. (2004). Ethics, reflexivity and ethically important moments in research. Qualitative Inquiry, 10 (2), 261-280. doi:10.1177/1077800403262360.

Hammersley, M., \& Atkinson, P. (2007). Ethnography. New York, NY: Routledge.

Jarman, N. (1999). Commemorating 1916, Celebrating Difference: Parading and Painting in Belfast. In A. Forty \& S. Küchler (Eds), The Art of Forgetting (171-195). Oxford: Berg.

Langmann, S. and Pick, D. (2014). Dignity and ethics in research photography. International Journal of Social Research Methodology, 17 (6), 709-721. doi:10.1080/136455792013.825473.

Lee, R. (1993). Doing research on sensitive topics. London, England: SAGE.

Lester, J., N., \& Anders, A., D. (2018). Engaging Ethics in Postcritical Ethnography: Troubling Transparency, Trustworthiness, and Advocacy. Forum: Qualitative Social Research, 19 (3), 1-18.

Mannay, D. (2014). Storytelling beyond the Academy: Exploring Roles, Responsibilities and Regulations in the Open Access Dissemination of Research Outputs and Visual Data. Journal of Corporate Citizenship, 54, 109-116.

McKay, S. (2008). Bear in Mind These Dead. London: Faber and Faber Ltd.

Muldoon, O. T. (2004). Children of the Troubles: The Impact of Political Violence in Northern Ireland. Journal of Social Issues, 60 (3), 453-468. doi:10.1111/j.00224537.2004.00366.x.

Nossiter, V., \& Biberman, G. (1990). Projective drawings and metaphor: Analysis of organizational culture. Journal of Managerial Psychology, 5, 13 -16.

O'Reilly, K. (2012). Key concepts in ethnography. London, England: SAGE.

Pauwels L. (2008). Taking and Using. Visual Communications Quarterly, 15 (4), 243257. doi: $10.1080 / 15551390802415071$.

Pink, S. (2007). Doing visual ethnography. London: Sage.

Prosser, J., \& Loxley, A. (2008). Introducing Visual Methods. ESRC National Centre for Research Methods Review Paper.

Rose, G. (2007). Visual methodologies. London: Sage

Smyth, M., \& Hamilton, J. (2003). The Human Costs of the Troubles. In O. Hargie, \& D. Dickson (Eds.), Researching the Troubles: Social Science Perspectives on the Northern Ireland Conflict 15-36). Edinburgh: Mainstream Publishing.

Stiles, D. R. (2004). Pictorial representation. In C. Cassell \& G. Symon (Eds.), Essential guide to qualitative methods in organizational research (127-139). London: Sage. 
Surmiak, A. (2018). Confidentiality in Qualitative Research Involving Vulnerable Participants: Researchers' Perspectives. Forum: Qualitative Social Research, 19 (3), 1-11.

Sweetman, P. (2009). Revealing habitus, illuminating practice: Bourdieu, photography and visual methods. The Sociological Review, 57 (), 491-511. doi: doi:10.1111/j.1467-954X.2009.01851.X.

Vince, R. (1995). Working with emotions in the change process: Using drawings for team diagnosis and development. Organisations and People, 2, 11-17.

Vince, R., \& Broussine, M. (1996). Paradox, defense and attachment: Accessing and working with emotions and relations underlying organisational change. Organization Studies, 17,1-21.

Wiles, R., Crow, G., Heath, S., \& Charles, V. (2007). The Management of Confidentiality and Anonymity in Social Research, International Journal of Social Research Methodology, 11 (5), 417-428. doi: 10.1080/13645570701622231.

Wiles, R., Prosser, J., Bagnoli, A., Clark, A., Davies, K., Holland, S., \& Renold, E. (2008). Visual Ethics: Ethical Issues in Visual Research. ESRC National Centre for Research Methods, 11.

Wiles, R., Coffey, A., Robinson, J. \& Heath, S. (2012a). Anonymisation and visual images: issues of respect, 'voice' and protection. International Journal of Social Research Methodology, 15 (1), 41-53. doi:10.1080/13645579.2011.564423.

Wiles, R., Coffey, A., Robinson, J. \& Prosser, J. (2012b). Ethical Regulation and Visual Methods: Making Visual Research Impossible or Developing Good Practice? Sociological Research Online, 17 (1), 1-10. doi:10.5153/sro2274. 